\section{A (IM)POSSIBILIDADE DA EDUCAÇÃO INTEGRAL}

\section{THE (UN)LIKELIHOOD OF INTEGRAL EDUCATION}

Talita Vidal ${ }^{1}$

Marcio Bernardino Sirino ${ }^{2}$

\begin{abstract}
Resumo: Neste artigo, as contribuições de aportes pós-estruturais e pós-fundacionais são mobilizadas para sustentar a (im)possibilidade de uma Educação Integral (EI). De uma perspectiva discursiva de interpretação dos fenômenos sociais, a El é entendida como um nome que se hegemoniza, passando a representar uma promessa de plenitude-por-vir humana e social. O nome Educação Integral é assumido, a partir da Teoria do Discurso de Ernesto Laclau, como um significante saturado de significados em disputas incessantes para fixar uma identidade plena e idealizada. Um processo em que lógicas ou narrativas fantasmáticas prometem a 'salvação' humana e uma plenitude-por-vir. Como material empírico, foram selecionadas quatro experiências de El: Centro Educacional Carneiro Ribeiro (CECR), Centro Integrado de Educação Pública (CIEP), Centro de Atenção Integral à Criança (CAIC) e o Programa Mais Educação (PME), assumidas como políticas curriculares, a partir das quais são interpretados sentidos dessas lógicas articulados e negociados nos textos políticos.
\end{abstract}

Palavras-chave: Educação Integral. Teoria do Discurso. Pós-Estruturalismo. Pós-Fundacionalismo. Lógicas fantasmáticas.

Abstract: The current article uses post-structural and post-foundational contributions to substantiate the (un)likelihood of Integral Education (IE). Based on a discursive perspective applied to interpret social phenomena, IE is herein understood as a hegemonized name that represents the promise of a human and social fullness-to-come. Based on Ernesto Laclau's Discourse Theory, the name Integral Education is assumed as a signifier saturated by meanings that are in continuous disputes to establish a full and idealized identity through a process whose phantasmic logics or narratives promise human 'salvation' and fullness-to-come. Four IE experiences were herein selected as empirical material, namely: Carneiro Ribeiro Education Center (CECR - Centro Educacional Carneiro Ribeiro), Integrated Center for Public Education (CIEP - Centro Integrado de Educação Pública), Comprehensive Child Care Center (CAIC - Centro de Atenção Integral à Criança) and More Education Program (PME - Programa Mais Educação); they were assumed as curricular policies adopted to interpret the meanings of the logics that are articulated and negotiated in political texts.

Keywords: Integral Education. Discourse Theory. Post-Structuralism. Post-Foundationalism. Phantasmic Logics.

Resumen: En este artículo se movilizan los aportes de los aportes posestructurales y posfundacionales para apoyar la (im) posibilidad de la Educación Integral (IE). Desde una perspectiva discursiva de interpretación de los fenómenos sociales, la IE se entiende como un nombre que se hegemoniza, convirtiéndose en una promesa de plenitud humana y social por venir. Se asume el nombre Educación Integral, de la Teoría del Discurso de Ernesto Laclau, como un significante saturado de significados en incesantes disputas para fijar una identidad plena e idealizada. Un proceso en el que las lógicas o narrativas fantasmales prometen la "salvación" humana y una plenitud por venir. Como material empírico, se seleccionaron cuatro experiencias de IE: Centro Educacional Carneiro Ribeiro (CECR), Centro Integrado de Educación Pública (CIEP), Centro de Atención Integral a la Infancia (CAIC) y Programa Mais Educação (PME), asumidos como políticas curriculares, a partir del cual se interpretan los significados de estas lógicas articuladas y negociadas en los textos políticos.

Palabras clave: Educación Integral. Teoría del discurso. Postestructuralismo. Posfundacionalismo. Lógica fantasma.

\footnotetext{
${ }^{1}$ Doutorado em Educação pela Universidade do Estado do Rio de Janeiro (UERJ). Professora Adjunta da Faculdade de Educação da Baixada Fluminense da UERJ e Procientista. Atua como docente do corpo permanente do PPGECCUERJ e do Programa de Pós-Graduação em Educação da Faculdade de Educação (ProPEd-UERJ). E-mail: p.talitavidal@gmail.com. Orcid: http://orcid.org/0000-0002-1442-0124.

${ }^{2}$ Doutorando em Educação pelo Programa de Pós-Graduação em Educação da Universidade do Estado do Rio de Janeiro (ProPEd/UERJ); Professor da Universidade Castelo Branco (UCB). E-mail: pedagogomarcio@gmail.com. Orcid: http://orcid.org/0000-0001-5874-6225.
} 


\section{INTRODUÇÃO}

Com base no movimento de apropriação da Teoria do Discurso (TD), de Ernesto Laclau e Chantal Mouffe (2010; 2015), que tem orientado nossas reflexões, temos buscado compreender uma proposta de Educação Integral como algo da ordem do (im)possível. Neste texto, desenvolvemos argumentos que têm sustentado essa compreensão, decorrente das contribuições de aportes pós-estruturalistas e da perspectiva pós-fundacionalista, assumida no estudo em que temos buscado problematizar sentidos de Educação Integral articulados em discursos em defesa dessa proposta.

Iniciamos o texto apresentando a TD e destacando as noções que têm sido produtivas para o desenvolvimento da pesquisa. Dessa forma, cabe destacar que Laclau e Mouffe (2010; 2015) são autores que se posicionam junto a tantos outros que têm buscado formular possibilidades de interpretação dos fenômenos sociais rompendo com axiomas essencialistas que caracterizam as metanarrativas modernas. Entendemos o projeto educacional moderno como uma dessas metanarrativas e identificamos que os discursos em defesa de uma Educação Integral articulam sentidos de uma mesma cadeia de equivalência em que a Educação é significada como possibilidade emancipatória, entendida como alcance da plenitude-por-vir humana.

\section{PASSAMOS, ENTÃO, A EXPLICITAR NOSSA APROPRIAÇÃO DA TEORIA DO DISCURSO (TD)}

Os questionamentos que Laclau e Mouffe (2015) fazem aos axiomas essencialistas e realistas têm como pressuposto a compreensão do espaço social como discursivo. Assumem que "toda configuração social é significativa" (p. 39) e que esses significados são sempre contingentes e precários e produzidos dentro de "um sistema de relações com outros objetos [que escapa à] mera materialidade referencial dos objetos" (p. 39). E concluem afirmando que entendem discurso como "conjunto sistemático de relações" (idem) e "que toda identidade ou objeto discursivo é constituído no contexto de uma ação" (p. 40). A própria ideia de realidade é compreendida como uma produção social de sentidos sobre o mundo, é resultado de operações simbólicas de nomeação daquilo que pode ser pensado, falado e atuado em diferentes contextos.

Essa compreensão sustenta a formulação de hegemonia em Laclau e Mouffe (2010) como tentativa discursiva de constituir o privilégio de um sentido único para os objetos sociais. O discurso assume uma primazia na TD como categoria teórico-analítica que busca interpretar os fenômenos sociais, em especial, os processos pelos quais determinados discursos, como o educacional, por exemplo, adquirem significativa estabilidade que nos permite identificá-los como hegemônicos. Laclau (2011) alerta para a precariedade dessa hegemonia, afirmando que ela só se tornou possível quando a demanda que passou a representar se esvaziou de significado. Um vazio que, segundo o autor, é resultado de um processo de saturação de sentidos.

É essa compreensão de hegemonia na TD que leva Burity (2008) a afirmar que ela também pode ser entendida como uma teoria dos processos de constituição de hegemonia, "concebida como uma operação discursiva que aspira à universalização de um discurso específico, buscando fixar sentidos de forma a alcançar a plenitude-por-vir que falta ao social” (COSTA; PEREIRA, 2012, p. 156).

Para Laclau (2011), o processo de constituição de hegemonia é permanente e visa ao fechamento do processo de significação. Visa à fixação de determinados significados particulares de forma que possam ser representados como totalidade garantindo aquilo que é ansiado, em dada ocasião política, como capaz de garantir a plenitude-por-vir que falta ao social (PEREIRA, 2010). Essa compreensão de um social que se move discursivamente, buscando uma completude que lhe falta, é desenvolvida por Laclau com base na teoria psicanalítica de Jacques Lacan (1997). O social é movido discursivamente por uma falta constitutiva.

Laclau e Mouffe (2010) explicam essa operação desenvolvendo a ideia de discurso como prática articulatória, como um momento da política em que diferentes demandas/elementos dispersos no campo da discursividade são ordenados em uma cadeia de equivalência; possibilitando esse ordenamento é um elemento que, na articulação, passa a ser significado como ameaça, um inimigo comum expulso da articulação e passa a funcionar como exterior constitutivo. Para Mouffe (2001), esse inimigo comum torna possível a identificação entre distintas demandas e formações discursivas. Quanto maior o número de 
demandas que uma dada cadeia de equivalência for capaz de articular, maior será seu potencial hegemônico. No entanto, ao integrar uma cadeia de equivalência, as demandas permanecem diferentes entre si, permanecem disputando significações na articulação, isso explica por que Laclau e Mouffe (2010) afirmam a precariedade da hegemonia: essa precariedade se deve ao processo incessante de proliferação de sentidos que orientam fenômenos sociais sem qualquer direção prévia ou intencionalidade racional.

As disputas por significação são tentativas de fixar e de estancar a produção de sentidos. Laclau (2011) e Laclau e Mouffe (2010) afirmam que essas tentativas de alcançar a completude são necessárias para o funcionamento do social, mas as reconhecem como impossibilidade por que esse fechamento nunca se realizará e sempre carregará "uma dimensão de indeterminação e de falta constitutiva, não dada a priori" (BURITY, 2008, p. 36).

Ao afirmar a impossibilidade de fechamento do social e/ou a impossibilidade daquilo que entendemos por sociedade, Laclau e Mouffe (2010) colocam em foco a dimensão ontológica da política. Assumem, como destacam Glynos e Howarth (2018, p. 55), "uma ontologia social que enfatiza a contingência radical e a incompletude estrutural de todos os sistemas de relações sociais". Apropriamonos dessas contribuições para pensar a produção de políticas curriculares como processo permanente de negociação e tentativas de fixar sentidos atribuídos à política.

Operamos com uma concepção de currículo a partir da qual assumimos as políticas de Educação Integral como políticas curriculares. Nossas reflexões têm como pressuposto uma compreensão discursiva e descentrada da política expressando um movimento de afastamento de abordagens que operam com enfoques racionalistas ancorados na ideia de que as políticas se sustentam em fundamentos fixos como o objetivo de fixar um conjunto de critérios a partir dos quais uma dada identidade possa ser constituída. Com Lopes (2015), afirmamos ser impossível constituir uma posição definitivamente consensual sobre esse conjunto de critérios e objetivos.

Dessa forma, o texto da política expressa um fechamento provisório no qual foi possível estabelecer algum nível de consenso entre inúmeras e diferentes demandas pedagógicas. No caso de nosso objeto de estudo, trata-se da impossibilidade de se constituir definitivamente um consenso sobre aquilo que está sendo significado como Educação Integral. Afirmamos que incontáveis e diferentes demandas disputam sentidos de Educação Integral. Portanto, assumimos que se trata de um significante em disputa e que se trata de um nome em torno de um significado como condição de mudança. $O$ privilégio discursivo concedido a esse nome passa a justificar e legitimar as políticas (CUNHA, 2015). Ou ainda, a hegemonização do sentido é produzida quando um nome passa a assumir o lugar da representação do Outro.

Desse modo, entendemos que o privilégio do nome "Educação Integral" não implica fechamento do processo de significação; pelo contrário, as disputas em torno desse significante produzem a sua saturação na medida em que sua hegemonização permanece constituída pela agregação incessante de elementos/momentos na articulação discursiva. Afirmar a Educação Integral como um nome implica compreendê-la como significante vazio.

O vazio do significante diz respeito a saturação de significados em disputa para preenchê-lo. Tentativas de fechamento que nunca se realizam. Nunca possibilitam afirmar, de uma vez por todas, um significado a um significante. A ideia de significante vazio é importante para pensar a produção de políticas, inclusive as políticas curriculares porque possibilita entender que adiantamentos simultâneos do significado não se tornam formalizados.

$\mathrm{Na}$ investigação que motiva esse texto, buscamos compreender a Educação Integral como um significante vazio com o entendimento de que essa demanda, esse nome, possibilita a articulação de demandas particulares em cadeias discursivas em que o Integral assume diferentes significados. Desde a ampliação do tempo na escola até uma concepção de integral como possibilidade de alcançar a formação humana completa (COELHO, 2009), capaz de garantir a plenitude-por-vir social e/ou individual.

Assumimos os discursos em defesa de uma Educação Integral como articulação discursiva de 
demandas diferenciais e, mesmo reconhecendo os riscos de ocorrer, em determinado momento, reducionismo, para a escrita deste texto elegemos alguns fundamentos e lógicas que orientam a constituição dessa formação discursiva.

\section{EDUCAÇÃO INTEGRAL COMO NOME SUPOSTO COMO CAPAZ DE GARANTIR A PLENITUDE-POR-VIR HUMANA E SOCIAL}

A título de ilustração, apresentamos a concepção de Educação Integral do Centro de Referências em Educação Integral ${ }^{3}$ :

A Educação Integral é uma concepção que compreende que a educação deve garantir o desenvolvimento dos sujeitos em todas as suas dimensões - intelectual, física, emocional, social e cultural - e se constituir como projeto coletivo, compartilhado por crianças, jovens, famílias, educadores, gestores e comunidades locais [grifo nosso].

Nessa proposta, a escola é assumida como lócus "essencial para assegurar que todos e todas tenham garantida uma formação integral" (idem).

Interpretamos que a aposta em uma formação integral carrega sentidos de uma plenitude-por-vir humana e social ansiada. Aposta na formação, por um tipo de educação, de uma identidade plena e completa. Uma identidade autorreferenciada. Uma pretensão sustentada naquilo que Stavrakakis (2017, p. 3) afirma ser uma "noção tradicional do bem". Uma noção "fálica e fantasística do bem". Uma noção de bem que implica uma forma simplista de conceber a subjetividade que tem como pressuposto a ideia de um sujeito "racional, autônomo, responsivo e dotado de certos direitos e faculdades mentais" (STAVRAKAKIS, 2017, p. 2).

Por sua vez, para Biesta (2017, p. 16) a educação é "sempre uma intervenção na vida de alguém; uma intervenção motivada pela ideia de que tornará essa vida, de certo modo, melhor: mais harmoniosa, mais perfeita - e talvez até mais humana". O autor destaca que a educação moderna se organiza em torno de uma "verdade particular sobre a natureza e o destino do ser humano [assumindo a existência de uma] conexão entre a racionalidade, a autonomia e a educação que se tornou a Santíssima Trindade do projeto do lluminismo" (BIESTA, 2017, p. 19, grifo do autor), deixando rastros (DERRIDA, 2008) em diferentes perspectivas e/ou abordagens educacionais, de certa forma herdeiras de uma concepção de educação "como o processo que ajuda as pessoas a desenvolver seu potencial racional para que possam se tornar autônomas, individualistas e autodirigidas, enquanto a racionalidade se tornou o marco moderno do que significa ser humano" (p. 19).

Buscamos compreender essa promessa de plenitude-por-vir anunciada por essa forma de pensar a educação apropriando-nos da ideia de lógica ou narrativa fantasmática formulada por Glynos e Howarth (2018).

Antes, porém, cabe trazer a explicação sobre os Estudos Críticos de Fantasia, em construção, por Jason Glynos e David Howarth. Os autores articulam a Teoria do Discurso com o campo da Psicanálise - em especial a Psicanálise Lacaniana - para investigar como os discursos produzidos por diferentes políticas, práticas, organizações e organizações práticas vão produzindo aderência nos diferentes sujeitos (GLYNOS, 2015). Esse feito acontece pela falta constitutiva dos sujeitos e pela tentativa constante de fechamento/preenchimento dessa falta, à luz da Psicanálise Lacaniana.

Segundo Glynos, Oliveira e Burity (2019), a Psicanálise ajuda a compreender fantasias presentes nos discursos conectando ou repelindo determinadas propostas por parte dos diferentes sujeitos. A fantasia aqui não significa ausência da realidade. Trata-se de fantasias constitutivas que possibilitam aos sujeitos organizarem a sua satisfação, o seu desejo de plenitude.

Para os autores as lógicas ou narrativas fantasmáticas anunciam a possibilidade de alcançar a plenitude-por-vir oferecendo aos sujeitos a oportunidade de organizar a satisfação de seus anseios. Esse sentimento de satisfação torna possível a ocultação da "contingência radical da realidade social" (GLYNOS; HOWARTH, 2018, p. 67) e ajuda a compreender a força do nome Educação Integral no campo e

${ }^{3}$ Disponível em: https://educacaointegral.org.br/conceito/. Acesso em: 19 maio 2020. 
ISSN 1983-1579

Doi: $10.22478 /$ ufpb.1983-1579.2020v13n3.52844

http://periodicos.ufpb.br/ojs2/index.php

nas políticas educacionais.

\subsection{A ordem do possível}

Para analisar a Educação Integral na perspectiva do possível, foi realizado um levantamento de experiências significativas no território brasileiro que potencializam essa discussão e a qualificam dentro de um conjunto de demandas que foram articuladas para que essas ações se materializassem e constituíssem uma provisória hegemonização no tempo-histórico-social a que foram propostas.

Nesse contexto, quatro experiências foram selecionadas: Centro Educacional Carneiro Ribeiro (CECR), Centro Integrado de Educação Pública (CIEP), Centro de Atenção Integral à Criança (CAIC) e Programa Mais Educação (PME) - pela capilaridade que possuíram, sendo as duas primeiras em nível local e duas últimas em âmbito nacional - estabelecendo, assim, uma articulação entre o micro e o macrocontexto (POWER, 2006).

Com base nas leituras de Anísio Teixeira (1959), pode-se compreender que a experiência do Centro Educacional Carneiro Ribeiro (CECR), também conhecida como "escola-classe x escola-parque" foi a primeira proposta, no Brasil, voltada para uma educação, supostamente, integral. Desenvolvida no bairro da Liberdade, em Salvador (BA), na década de 1950, a proposta previa a instalação de quatro escolasclasse do ensino primário para um total de 1.000 alunos, em dois turnos de 500 estudantes em cada. As escolas-classe eram formadas por 12 salas de aula cada uma, áreas cobertas, gabinetes médico e dentário, instalações para administração, jardins, hortas e áreas livres. Para essas quatro unidades de escolasclasse, uma unidade de escola-parque era projetada com sete pavilhões para as denominadas "práticas educativas". Na escola-parque, os alunos eram agrupados por suas preferências, numa área de $42.000 \mathrm{~m}^{2}$, com um ginásio de esportes, um pavilhão de atividades sociais, um teatro, uma biblioteca, um restaurante, uma lavanderia, uma padaria e um banco.

As atividades pedagógicas eram oferecidas por diferentes setores. Os alunos recebiam alimentação e atendimento médico-odontológico e estudavam na divisão turno x contraturno - sendo num turno na escola-classe, que estaria voltada para a instrução e, no outro, na escola-parque - que estaria relacionada ao setor da educação.

Com base nas contribuições de Vítor Paro (1988), entende-se que os Centros Integrados de Educação Pública (CIEPs), criados por Darcy Ribeiro, na década de 1980, durante o governo de Leonel Brizola, foram inspirados na experiência de Anísio Teixeira tratada no parágrafo anterior. Os CIEPs foram projetados pelo arquiteto Oscar Niemeyer para todo o Estado do Rio de Janeiro. Foram construídos cerca de $500 \mathrm{CIEPs}$, nos quais mesclavam-se atividades escolares e outras atividades de caráter mais socioeducativo, num mesmo espaço, em turno integral. Os CIEPs possuíam três blocos: no bloco principal, com três andares, ficavam as salas de aula, o centro médico, a cozinha e o refeitório; no segundo bloco, havia o ginásio coberto com arquibancada e vestiário; no terceiro bloco, de forma octogonal, mantinhase a biblioteca e, em cima dela, a moradia para alunos residentes.

Pelas reflexões de Sobrinho e Parente (1995), percebe-se que os inicialmente denominados Centros Integrados de Atenção à Criança e ao Adolescente (CIACs) foram criados, na década de 1990, por Fernando Collor de Mello, no Projeto Minha Gente, com o objetivo de articular a Educação, a Saúde, a Assistência Social e a Promoção Social para o desenvolvimento das crianças e adolescentes. A meta proposta pelo Governo Federal, à época, foi de construção de $5.000 \mathrm{CIACs}$, em áreas periféricas de todo o território nacional - carecendo de um espaço de $16.000 \mathrm{~m}^{2}$. Com o impeachment de Collor, em 1992, e a entrada de Itamar Franco na presidência, a política teve alteração na sua nomenclatura. Os CIACs passaram a se chamar Centros de Atenção Integral à Criança (CAICs); a alteração também se deu no Projeto Minha Gente que, consecutivamente, foi substituído pelo Programa Nacional de Atenção à Criança e ao Adolescente (Pronaica), que exigia uma articulação entre os sistemas federais, estaduais e municipais. Apesar da restruturação da denominação, a proposta pedagógica permaneceu.

Por meio das problematizações envidadas por Leclerc e Moll (2012), identifica-se que o Programa Mais Educação (PME), instituído pela Portaria Interministerial $n^{\circ} 17 / 07$ e regulamentado pelo Decreto $n^{\circ}$ 
7.083/10, constituiu-se como estratégia do Ministério da Educação para induzir a ampliação da jornada escolar e a organização curricular na perspectiva da Educação Integral. Vinculado ao Plano de Desenvolvimento da Educação (PDE), o PME tinha como objetivo fomentar a Educação Integral nos municípios, nos estados e no Distrito Federal, em unidades escolares que atendiam a crianças, adolescentes e jovens no contraturno, com atividades socioeducativas - dentro ou fora do espaço escolar, dinamizadas por monitores e/ou oficineiros dentro dos seguintes macrocampos: Acompanhamento pedagógico; Meio ambiente; Esporte e lazer; Direitos Humanos; Cultura e Arte; Cultura digital; Prevenção e promoção da saúde; Comunicação e uso de mídias; Iniciação à investigação das Ciências da Natureza e Educação econômica. Previa-se nesse programa a articulação da escola com outros espaços sociais educativos - tendo em vista sua aproximação com o Movimento Cidades Educadoras, criado em 1990 em Barcelona, Espanha - e ações integradas que estivessem previstas no projeto político-pedagógico (PPP) e em articulação com os componentes curriculares da Base Nacional Comum Curricular (BNCC), conectando diferentes saberes e valorizando diversas formas de produção de conhecimento.

A fim de "didatizar" esta discussão, o quadro a seguir apresenta uma síntese dessas experiências de Educação Integral e os benefícios que elas trouxeram para a educação pública brasileira.

Quadro 1 - Experiências de Educação Integral e suas potências

\begin{tabular}{|c|c|}
\hline $\begin{array}{l}\text { Experiências } \\
\text { de Educação } \\
\text { Integral }\end{array}$ & Potências significadas \\
\hline CECR & $\begin{array}{l}\text { "Que a escola eduque, forme hábitos, cultive aspirações, prepare realmente a } \\
\text { criança para a sua civilização tão difícil por ser uma civilização técnica e industrial } \\
\text { e ainda mais complexa por estar em mutação permanente”. } \\
(\text { TEIXEIRA, 1959, p. 2) }\end{array}$ \\
\hline CIEPS & $\begin{array}{l}\text { “O CIEP se propõe como uma 'escola-casa' que pretende respeitar os direitos das } \\
\text { crianças. Assumindo como verdadeiros alguns dos supostos fatores pelos quais } \\
\text { os alunos não permanecem nas escolas ou não obtêm rendimento adequado } \\
\text { (desnutrição, dificuldades para a aquisição de material escolar, doenças } \\
\text { infecciosas, deficiências de saúde - problemas dentários, visuais e auditivos), o } \\
\text { CIEP se propõe a superar esses obstáculos mediante programas de alimentação, } \\
\text { subsídios aos pais e programas de atendimento médico-odontológico, de modo } \\
\text { que os alunos tenham as melhores condições para aprender”. } \\
\text { (PARO, 1988, p. 20) }\end{array}$ \\
\hline CAICs & $\begin{array}{l}\text { “O programa tem seu objetivo, suas estratégias, seus pressupostos e seus } \\
\text { fundamentos. Seu objetivo é a 'superação das carências das crianças e dos } \\
\text { adolescentes'. Suas estratégias: 'a integração dos serviços', 'o atendimento } \\
\text { integral', 'a participação da comunidade' e 'a gestão local pelas prefeituras e } \\
\text { instituições comunitárias'. Seus pressupostos: a inovação e a flexibilidade. Seus } \\
\text { fundamentos estão centrados na urgência de reverter as precárias condições de } \\
\text { vida } \\
\text { de parte das crianças e dos adolescentes brasileiros, nos posicionamentos e } \\
\text { compromissos internacionais e na Constituição Federal de 1988, que estabelece } \\
\text { nos seus dispositivos relativos à área social importância primordial a essa } \\
\text { questão, para o que o Estado deverá assumir e dispensar apoio e atenção } \\
\text { especiais, provendo os meios necessários pelo desenvolvimento de programas } \\
\text { de assistência social à criança e ao adolescente”. } \\
\text { (SOBRINHO; PARENTE, 1995, p. 16) }\end{array}$ \\
\hline PME & $\begin{array}{l}\text { "A estratégia indutora nacional representada pelo Programa Mais Educação tem } \\
\text { explicitado, em seus avanços e desafios, questionamentos, reflexões e novas } \\
\text { práticas acerca da necessária reorganização curricular em tempos ampliados. Tal } \\
\text { processo ganha significado diferenciado quando o acúmulo de experiências que }\end{array}$ \\
\hline
\end{tabular}




\begin{tabular}{|l|l|}
\hline & $\begin{array}{l}\text { dialogam com as culturas populares, juvenis e infantis começa a ganhar espaço } \\
\text { no cotidiano das escolas". } \\
(\text { LECLERC; MOLL, 2012, p. 107) }\end{array}$ \\
\hline
\end{tabular}

Fonte: Elaboração dos autores, 2020.

Esse desenho contextual oportuniza a compreensão da possibilidade de construção da Educação Integral, quer seja quando se previa o cultivo de "aspirações" no CECR, quando houve busca por oferecer aos estudantes "melhores condições para aprender" nos CIEPs, quando se evidenciava a dispensa, por parte do Estado, de "apoio e atuação especial" às crianças nos CAICs ou mesmo quando se projetava maior diálogo entre os saberes escolares e as culturas populares, no PME.

Demandas diferenciais que, postas numa cadeia de equivalência, são articuladas discursivamente para evidenciar a necessidade de fixação do nome Educação Integral no solo brasileiro.

Os aspectos sintetizados de cada experiência analisada dialogam com a compreensão mais ampliada de educação - quiçá 'integral' - pela dimensão holística de emancipação (BURITY, 1994) que possuem para com crianças, jovens e adultos, sobretudo das camadas empobrecidas da população brasileira.

Mas discursivamente faz-se necessário problematizar este nome, "Educação Integral”, a fim de discutir em que medida essas experiências não carregam, também, fantasias da ordem do impossível que formatam sujeitos e condicionam práticas educativas fundamentadas numa suposta visão de plenitudepor-vir. Esse aspecto será ampliado na próxima seção.

\subsection{A ordem do impossível}

A fim de desbravar as impossibilidades de construção da Educação Integral, as experiências utilizadas anteriormente foram acionadas. No entanto, agora o foco se alinha com a identificação de lógicas fantasmáticas que orientam os processos de hegemonização dessas propostas, que, vistas de forma crítica, colocam o nome "Educação Integral” na esfera da impossibilidade.

Impossibilidade que afirmamos se pautar em fundamentos realistas a priori. Na ideia de que "em algum lugar" está assentada "uma verdade" sobre o mundo e sobre as coisas que acontecem no mundo e que a formação "adequada", integral, nos possibilitaria acessar essa verdade e tomar decisões melhores. A Educação Integral pensada nessa perspectiva é uma impossibilidade. Porque não existe um a priori que possa, de forma inequívoca, atestar a legitimidade de qualquer decisão. Logo, nenhuma formação pode dar conta dessa expectativa. O que é melhor também faz parte de uma rede de disputas no campo de discursividade que constitui o social.

Nesse contexto, quando o CECR estabeleceu uma relação direta entre dar "saúde e alimento" à criança para que ela possa ser educada, estabelece uma relação direta entre o significante 'educação' com o adjetivo 'integral' e o significado de 'melhoria' na qualidade da educação proposta.

Dando continuidade, quando os CIEPs são significados como uma escola "diferente" porque oferece "melhores" condições de trabalho entre o educador e o educando, novamente pode ser identificada a perspectiva do "melhorismo", como se essa escola, sozinha, pudesse dar conta das mazelas educacionais e garantir essa "Educação Integral".

De igual forma, quando os CAICs trazem a proposta de integração nas ações desenvolvidas como forma de assegurar "melhores" condições de vida, mais uma vez, a lógica do "melhorismo" é acionada, apresentando uma relação de causalidade entre a integração de diferentes órgãos públicos e a "melhoria" na vida das pessoas.

Por fim, quando o PME propõe que a atividade socioeducativa desenvolvida, num tempo ampliado, deve ser acompanhada pela intensidade do tempo, que é significada como "qualidade" permite a associação dessa articulação com a busca do "melhorismo" na educação, que, sendo "integral", automaticamente será de "qualidade". 
Cabe, neste momento, sinalizar os verbos em destaque nos parágrafos anteriores: dar, oferecer, assegurar e dever. Os três primeiros denotam ação externa ao sujeito; o último revela uma condição sine qua non, sem a qual não é possível construir a "Educação Integral”. Fantasias essas - de imposição e de condicionamento - que podem ser observadas no quadro a seguir, com excertos de cada uma das experiências analisadas.

Quadro 2: Experiências de Educação Integral e suas fantasias

\begin{tabular}{|c|c|}
\hline $\begin{array}{l}\text { Experiências } \\
\text { de Educação } \\
\text { Integral }\end{array}$ & Fantasias significadas \\
\hline CECR & $\begin{array}{l}\text { "E, além disso, desejamos que a escola dê saúde e alimento à criança, visto não } \\
\text { ser possível educá-la no grau de desnutrição e abandono em que vive". } \\
\text { (TEIXEIRA, 1959. p. 2) }\end{array}$ \\
\hline CIEPS & $\begin{array}{l}\text { "O CIEP é uma escola diferente porque oferece melhores condições de trabalho } \\
\text { com o aluno". } \\
\text { (PARO, 1988, p. 32-33) }\end{array}$ \\
\hline CAICs & $\begin{array}{l}\text { "Como parte de suas políticas sociais, o Governo Federal propôs-se a } \\
\text { desenvolver, a partir de 1990, ações integradas de educação, saúde, assistência } \\
\text { e promoção social para crianças e adolescentes, como forma de assegurar } \\
\text { melhores condições de vida a esse segmento da população". } \\
\text { (SOBRINHO; PARENTE, 1995, p. 5) }\end{array}$ \\
\hline PME & $\begin{array}{l}\text { "Falamos em tempo ampliado e qualificado como aquele que explicita e articula } \\
\text { atividades educativas diferenciadas e que, ao fazê-lo, contribui para a formação } \\
\text { integral do aluno, para a superação da fragmentação e do estreitamento } \\
\text { curricular e da lógica educativa demarcada por espaços físicos e tempos } \\
\text { delimitados rigidamente nos diferentes momentos da sua trajetória pela } \\
\text { Educação Básica. Nesse sentido, entende-se que a extensão do tempo - } \\
\text { quantidade - deve ser acompanhada por uma intensidade do tempo - qualidade } \\
\text { - nas atividades que constituem a jornada ampliada na instituição escolar”. } \\
\text { (LECLERC; MOLL, 2012, p. 106-107) }\end{array}$ \\
\hline
\end{tabular}

Fonte: Elaboração dos autores, 2020.

É possível identificar que as quatro experiências de Educação Integral apresentadas carregam em comum o desejo de uma busca pela plenitude-por-vir humana, que é fruto da compreensão desse nome como "formação completa" (COELHO, 2009, p. 90). Ou seja: na tentativa de alcançar a completude desse ser humano e preencher a falta constitutiva que o caracteriza, entende-se que a educação - significada como "integral" - teria condições de produzir esse estancamento no processo discursivo de significação e dar conta de oferecer mais qualidade - em tempo parcial ou mesmo ampliado - às crianças e adolescentes que fazem parte do processo de ensino-aprendizagem.

Ao mesmo tempo, percebe-se nessa lógica uma tentativa de singularizar a concepção de ser humano, ancorada num humanismo que, segundo Levinas (1981, p. 128, apud BIESTA, 2017, p. 21), "não é suficientemente humano", e formatar um sujeito adequado, digno para essa Educação "Integral” aquele que tem saúde e alimento; aquele que se relaciona bem com o educador; aquele que tem condição de mudar sua vida e aquele que tem o tempo ampliado com intensidade de ações socioeducativas, dentre muitos outros sentidos que podem ser identificados e articulados para fixar - ainda que de forma provisória, contingente e precária - uma forma de ser "humano".

Essa perspectiva impossibilita a construção de uma "Educação Integral" tendo em vista a sua articulação com fantasias (desejos) de melhorismo, totalidade, plenitude-por-vir, padronização e estancamento de outros processos de significação - imposições a priori como se fossem a melhor opção para os diferentes indivíduos ou cidadãos (RUSSEL, 2018). 
ISSN 1983-1579

Doi: 10.22478/ufpb.1983-1579.2020v13n3.52844

http://periodicos.ufpb.br/ojs2/index.php

\section{FICANDO POR AQUI SEM ENCERRAR O DEBATE}

Educação Integral, significada por Cavaliere (2009) como um conceito em construção, vem sendo objeto de investigação de diferentes pesquisadores no Brasil. Entendemos que a autora defende como "construção conceitual” as tentativas de fixar um sentido para Educação Integral no cenário educacional brasileiro. Tentativas, pois, de acordo com os aportes teóricos utilizados nesta produção, a fixação será sempre provisória, contingente e precária - fruto de processos discursivos de articulação. Elas implicam disputas por significação que, se por um lado esvaziam o significante "Educação Integral", por outro contribuem para hegemonizar esse nome, mesmo que carregado de ambivalências e imprecisões que reconhecemos e que nos autorizam a afirmar que a Educação Integral é da ordem do 'possível' e Educação Integral é da ordem do 'impossível'.

É da ordem do possível na medida em que abre lugar para pensar o desenvolvimento de ações socioeducativas que possam ampliar espaçostempos de ressignificação dos processos curriculares na perspectiva do empoderamento dos diferentes sujeitos. E é da ordem do impossível quando continuamos a pensar o 'Integral' com base em modelos padronizados de formação humana, assumindo os riscos que esses projetos oferecem à emergência das diferenças em nome de narrativas fantasmáticas que prometem a 'salvação' humana, que prometem uma plenitude-por-vir.

Nosso investimento não visa argumentar contra a Educação Integral, mas, sim, problematizar os fundamentos que sustentam as certezas sobre as possibilidades de uma educação concebida como integral. Buscamos destacar as disputas de sentidos em torno do que está sendo significado como integral alertando para a impossibilidade de fechamento definitivo desse processo de significação.

Como afirma Lopes (2013), a proliferação e as disputas incessantes de sentidos é que garantem a hiperpolitização e tornam a democracia possível. Na mesma linha, argumentamos quanto aos riscos de narrativas fantasmáticas que prometem uma plenitude-por-vir. A promessa sedutora pode nos levar a abdicar da construção de relações mais justas, democráticas e inclusivas, o que se contrapõe ao projeto de sociedade que uma Educação Integral acena como possibilidade.

Por fim, argumentamos que a possibilidade de uma educação que possa se aproximar da ideia de integral depende da aceitação da contingência e da ambivalência que caracterizam as relações sociais. Concordamos com Stavrakakis (2017, p. 11) quando afirma que "é aí, porém, que reside a beleza da coisa: isso nos abre à contingência, ao fato de que podemos tentar influenciar a significação, mas que, de forma alguma, podemos controlá-la de antemão".

\section{REFERÊNCIAS}

BIESTA, Gert. Para além da aprendizagem: educação democrática para um futuro humano. $1^{\text {a }}$ reimp. Belo Horizonte: Autêntica 2017.

BURITY, Joanildo A. Da emancipação à liberdade. In: MOURA, Alexandrina S. (Org.) Utopia e formações Sociais. Recife: Massangana, 1994. p. 29-45.

BURITY, Joanildo Albuquerque. Discurso, política e sujeito na Teoria da Hegemonia de Ernesto Laclau. In: MENDONÇA, Daniel de; RODRIGUES, Léo Peixoto (Org.). Pós-Estruturalismo e Teoria do Discurso: em torno de Ernesto Laclau. Porto Alegre: EDIPUCRS, 2008. p. 35-51.

CAVALIERE, Ana Maria. Conceito de educação integral é um conceito em construção. Portal do Professor, Brasília, $\quad$ n. 20, 2009. 20 Disponível http://portaldoprofessor.mec.gov.br/conteudoJornal.html?idConteudo=526. Acesso em: 10 maio 2020.

COELHO, Lígia Martha Coimbra da Costa. História(s) da educação integral. Em Aberto, Brasília, v. 22, n. 80, p. 83-96, abr. 2009.

COSTA, Hugo Heleno C.; PEREIRA, Talita Vidal. Interdisciplinaridade: um significante flutuante nos currículos de Ciências e Geografia. Poíesis Pedagógica, v. 10, n. 2, p. 155-175, ago./dez. 2012. 
CUNHA, Érika Virgílio Rodrigues da. Política curricular de ciclos como o nome da democracia: o caso de Rondonópolis (MT). 2015. 254 f. Tese (Doutorado em Educação) - Faculdade de Educação, Universidade do Estado do Rio de Janeiro, Rio de Janeiro, 2015.

DERRIDA, Jacques. Gramatologia. São Paulo: Perspectiva, 2008.

GLYNOS, Jason Ernesto. The tension dweller: on paradox, political discourse and affect. Pléyade, n. 16, p. 49-55, jul./dez. 2015.

GLYNOS, Jason; HOWARTH, David. Explicação crítica em Ciências Sociais: a abordagem das lógicas. In: LOPES, Alice Casimiro; OLIVEIRA, Anna Luiza A. R. Martins; OLIVEIRA, Gustavo Gilson Souza de (Orgs.). A teoria do discurso na pesquisa em educação. Recife: Ed. UFPE, 2018. p. 53-103.

GLYNOS, Jason; OLIVEIRA, Gustavo Gilson Souza de; BURITY, Joanildo. Critical fantasy studies: neoloberalism, education and identification. An interview with Jason Glynos. Série-Estudos, Campo Grande, v. 24, n. 52, p. 145-170, set./dez. 2019.

LACAN, Jacques. Écrits: a selection. London: Tavistock, 1997.

LACLAU, Ernesto. Emancipação e diferença. Rio de Janeiro: EdUERJ, 2011.

LACLAU, Ernesto; MOUFFE, Chantal. Hegemonía y estrategia socialista. Hacia una radicalización de la democracia. $3^{\text {a }}$ ed. Buenos Aires: Fondo de Cultura Económica, 2010.

LACLAU, Ernesto; MOUFFE, Chantal. Pós-marxismo sem pedido de desculpas. In: LOPES, Alice C.; MENDONÇA, Daniel de (Orgs.). A teoria do discurso de Ernesto Laclau. Ensaios críticos e entrevistas. São Paulo: Annablume, 2015. p. 35- 72.

LECLERC, Gesuína de Fátima Elias; MOLL, Jaqueline. Programa Mais Educação: avanços e desafios para uma estratégia indutora da Educação Integral e em tempo integral. Educar em Revista, Curitiba, n. 45, p. 91-110, jul./set. 2012.

LOPES, Alice Casimiro. Teorias pós-críticas, política e currículo. Educação, Sociedade \& Culturas, n. 39, p. 723, 2013.

LOPES, Alice Casimiro. Por um currículo sem fundamentos. Linhas Críticas, v. 21, p. 445-466, 2015.

MOUFFE, Chantal. Identidade democrática e política pluralista. In: MENDES, Candido (Coord.). Pluralismo cultural, identidade e globalização. Rio de Janeiro: Record, 2001. p. 410-430.

PARO, Vítor. Escola de tempo integral: desafio para o ensino público. São Paulo: Cortez; Autores Associados, 1988.

PEREIRA, Talita Vidal. As contribuições do paradigma pós-estruturalista para analisar as políticas curriculares. Espaço do Currículo, v. 3, n. 1, p. 419-430, mar./set. 2010.

POWER, Sally. O detalhe e o macrocontexto: o uso da teoria centrada no Estado para explicar práticas e políticas educacionais. Olhar de professor, Ponta Grossa, v. 9, n. 1, p. 11-30, jan./jun. 2006.

RUSSEL, Bertrand. Educação e ordem social. Rio de Janeiro: EdUERJ, 2018.

SOBRINHO, José Amaral; PARENTE, Marta Maria de Alencar. CAIC: solução ou problema? Rio de Janeiro: IPEA, 1995. (Resultado da pesquisa do IPEA - Instituto de Pesquisa Econômica Aplicada).

STAVRAKAKIS, Yannis. Populismo para atravessar a fantasia? Entrevista concedida a Thomás Zicman de Barros. Revista Lacuna, v. 1, n. 4, p. 1-16, nov. 2017. Disponível em: https://revistalacuna.com/2017/11/20/n411/. Acesso em: 30 abr. 2020.

TEIXEIRA, Anísio. Centro Educacional Carneiro Ribeiro. Revista Brasileira de Estudos Pedagógicos, Rio de Janeiro, v. 31, n. 73, p. 78-84, jan./mar. 1959.

Recebido em: 28/05/2020

Alterações recebidas em: 02/07/2020

Aceito em: 30/09/2020

Publicado em: 10/11/2020 